\title{
Cellulose Ether-Based Liquid Crystal Materials: Review Article
}

\author{
Altaf H. Basta ${ }^{1, *}$, Vivian F. Lotfy ${ }^{1}$, Jehane A. Micky ${ }^{2}$ and Aya M. Salem ${ }^{1}$ \\ ${ }^{1}$ Cellulose and Paper Dept., National Research Centre, El-Buhooth Stree, Dokki-12622, Cairo, Egypt \\ ${ }^{2}$ Department of Chemistry, Faculty of Science (Girl's), Al-Azhar University, Nasr City, Cairo, Egypt
}

\begin{abstract}
The development of liquid crystal materials via nanotechnology has become an interesting subject of research in optical material chemistry. One of the significant nanomaterials is cellulose-based nanoparticles. In this review article, we highlighted the classification of liquid crystal materials (LCs), and types of cellulose-NPs and their characterization as LCs materials. Finally, we present our promising data on the synergistic effect of cellulose-NPs on liquid crystal behavior of ethyl cellulose- and hydroxypropyl cellulose- nanocomposites.
\end{abstract}

Keywords: Cellulose ether, Cellulose-based nanoparticles, Rheology, Polarizing microscopy, Liquid crystal materials.

\section{INTRODUCTION}

For many decades, polymers, especially natural polymers, e.g., cellulose-based materials, have been used in many applications which servant, pharmaceutical, medical, textiles, artificial wood, paper, water desalination and purification, as well as food industries [1-9]. With regard to optical applications, these biopolymers are also used in synthesizing fluorescence and LC- materials [10, 11]. These materials are defined as a material with properties between liquid and solid crystal. Where it flows similar to liquid, and its molecules may be oriented like a crystal.

This material was first discovered in 1888 by Austrian botanical physiologist Friedrich Reinitzer-KarlFerdinands Universitat, when he examined the physical and chemical properties of cholesterol. There are many different types of liquid-crystal phases, which can be characterized by their different optical properties such as birefringence [12]. When the temperature-induced formation of the phases of Liquid crystal is known thermotropic LCs, while Lyotropic LCs depend on temperature together with the concentration of the liquid crystal molecules in a solvent (usually water). Thermotropic liquid crystals, based on phase transition depending on temperature, are divided as: Nematic, Smectic, and Cholesteric, as the names established by Friedel (1922). For the lyotropic phases, the LC compound in solvent as a fluidity system has another freedom of concentration to provide different phases

*Address correspondence to this author at the Cellulose and Paper Dept., National Research Centre, El-Buhooth Stree, Dokki-12622, Cairo, Egypt; E-mail: Altaf_Halim@yahoo.com, Altaf_basta2004@yahoo.com
[13]. Application of LCs materials as temperature indicators, analytical metrology, cancer diagnostics and non-destructive testing of materials were suggested in 1960; while in display technology, in 1968. George Heilmeier was the first prototype of LCD's, which used the LCs as a replacement for the cathode ray vacuum tube used in television. Moreover, LCs have wide applications in high modulus fibres and opto-electronic devices, sensors, and detectors [14].

Regarding cellulose-based LC materials, hydroxypropyl cellulose (HPC) and ethyl cellulose (EC) are the important cellulose derivative, besides their wide applications as a thickening agent, fillers, dietary fiber, it also exhibits liquid crystal phase in different solvents, with both lyotropic and thermotropic characteristics. This property originated from the chemical structure of such a derivative, which includes 1ry and 2ry hydroxyl propyl groups together with residual hydroxyl moieties. HPC is reported by Werbowyl and Gray (1976), as a cholesteric phase in aqueous solutions. It shows an upper consolute solution temperature at around $40^{\circ} \mathrm{C}$. At room temperature, it forms a fluid mesophase. The solutions show the iridescent colors characteristic of a chiral nematic (cholesteric) liquid crystal. Esterification of HPC was found to form LC- phases [15-19].

This article was focused on reviewing the route of synthesizing cellulose nanomaterials, and its role on liquid crystal performance, individually and in nanocomposites with HPC and EC.

\section{CLASSIFICATION OF LIQUID CRYSTALS (LCs)}

LC phases are considered the fourth state of matter along with solid, liquid and gas. They regarded an 


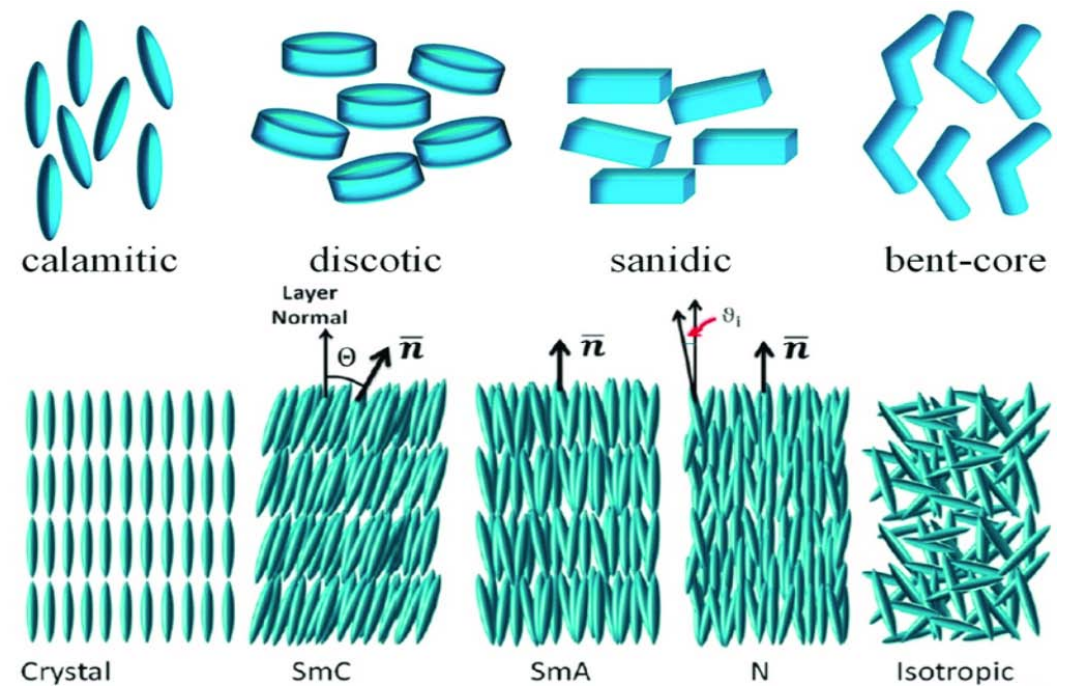

Figure 1: Various shapes of liquid crystal molecules [27].

intermediate phase of matter possessing both order (like solid) and mobility (like liquid), hence the term mesophase in Greek means between. Shape molecules of LC phases are rodlike (calamitic), lathlike (sanidic) or dislike (discotic) [20,21]. Furthermore, exotic designs like banana-shaped mesogens [22] pyramids [23] and shuttlecocks [24] have been shown to be capable of self-organization. Besides a rigid interior, mesogens need to possess some flexible compartments at their proximity to ensure sufficient movability. Rigid parts usually consisted of aromatic rings connected via bonds showing full or partial double bond character. In addition to compounds with low molecular weight, there are polymeric compounds that exhibit liquid crystalline behavior [25, 26]. Figure 1 summarized the type of liquid crystal molecules according to Reference [27].

For another classification is used to distinguish between lyotropic and thermotropic liquid crystals, the former appears in nature and in living organisms, acquiring mobility by the addition of the solvent which depends on the concentration of molecules and the temperature of the system for the formation of liquid crystals $[28,29]$; while the latter is the more commonly seen liquid crystal, based only on the temperature of the system. Also, the shape of molecules dictates the orientational order and thermal motion gives mobility. The materials which exhibit both properties (thermotropic and lyotropic) are called amphotropic. Nowadays, light is known to be an additional stimulus to introduce liquid crystalline behavior [30, 31]. The simple LC phase is the nematic phase (Figure 2), where rod-like mesogens point in average to the same direction. The centers of mass are distributed randomly, and they are free to move, like in a fluid, but their average orientation will remain the same, similar to a crystal. Thus, the material is anisotropic. The order parameter (equation 1) quantifies the variation of the mesogen's orientation from the average vector (director).

$S=\frac{1}{2}(3 \cos \theta-1) \theta$

where theta $(\theta)$ is the angle between the mesogen's long axis and the director, while $(3 \cos \theta-1)$ denotes the statistical average. In a perfect crystal (solid) $S$ is equal to 1 , while in an isotropic liquid it is 0 . If all molecules would be aligned perpendicular to the director, the value for $S$ is -0.5 . The typical range of $S$ is between 0.3 and 0.7 for liquid crystals. The second major class of rod-like mesogen's is the smectic phase (Figure 2). In addition to a preferred orientation, the mesogen's are well placed in a layered structure but have no fixed position within the layer. There are several smectic phases attributed with letters in accordance with their discovery. For example, in a smectic, A phase the mesogen's long axes are aligned parallel to the layer normal, while in smectic $C$ they are tilted at a certain angle. Hence the order parameter $S$ is higher for these phases than for nematic. Another type of liquid crystalline phase with two-dimensional order is the columnar phase, formed by disk-shaped molecules. Here the center of mass is along the centerline of one column. The columns are organized in a hexagonal or rectangular geometry perpendicular to the column.

With regard to rod-like species, there is the chiral nematic phase where the mesogens tend to align in nematic layers. 


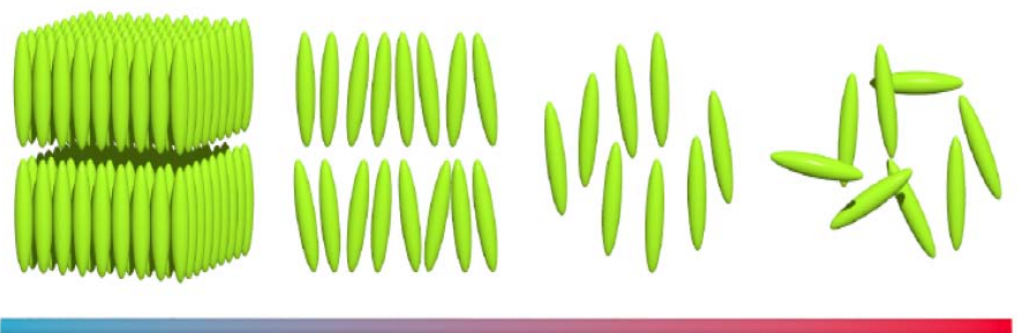

Figure 2: From left to the right [temperature increases, $\mathrm{S}$ decreases (order parameter)]: Crystal, smectic LC, nematic LC, isotropic (liquid).

Due to the chirality, a helical twist is introduced to the director field. Hence chiral nematics consist of nematic layers, but the director rotates along an axis normal to the layers. Chiral nematic phases are formed by cholesterol derivatives, as a result of their intrinsic chirality without dopants. Thus, chiral nematic phases are referred to as cholesteric liquid crystals (CLC). An important value for characterizing this state is the pitch $\mathrm{p}$. It is the distance needed for one 360 rotation of the director and covers the range from $200 \mathrm{~nm}$ to several $\mathrm{mm}$ (see Figure 3).

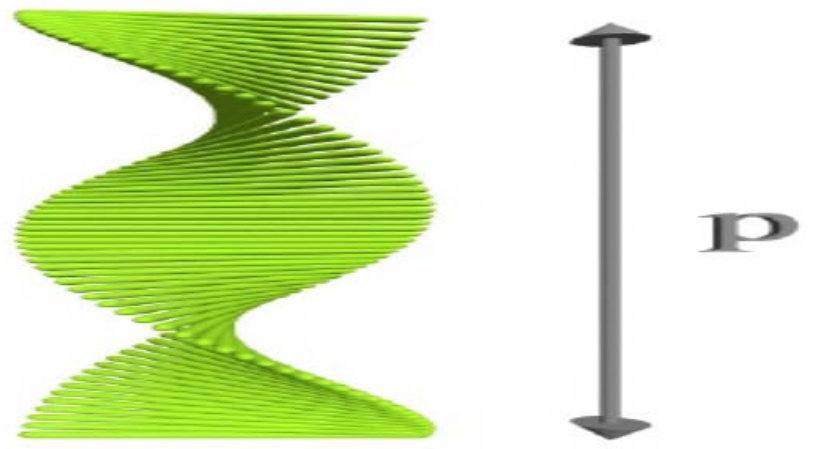

Figure 3: The helical superstructure of calamitc mesogens in a cholesteric liquid crystal (Pitch $p$ ) handed twist.

Positive values for $p$ are assigned to right-handed twist sense, negative for a left-handed twist. A righthanded twist sense is present if, viewing along the helical axis, the molecules rotate clockwise during going away from the viewer's point. If the CLC is a mixture of a dopant and an achiral LC the pitch is defined as

$P=\frac{1}{H T P * G}$

Where $C$ is the weight concentration of the dopant and HTP is its helical twisting power. The sign and value of HTP depend on the detailed molecular structure of the chiral dopant, the interaction with the host LC and the temperature, but to date, no universal relationship has been found [32]. The pitch and the resulting optical properties can be changed by using external stimuli, e.g., the temperature change, mesogen and dopant concentration, sensitivity to special additives, light and electric fields [33-36].

\section{ORIGIN OF LIQUID CRYSTAL MATERIALS}

\subsection{Non-Cellulose Based Liquid Crystal}

Some heterocyclic compounds and detergents can form LC mesophases [37, 38]. Besides low molecular weight LC, there are lots of polymer substances that exhibit liquid crystalline behavior [25, 26]. Daniel Vorlander, who played a major role in the discovery and synthesis of liquid crystalline materials, already synthesized oligomers with 1 to 3 linked mesogens. He synthesized Poly ( $p$-benzamide) and reported this polymer as a birefringent powder that would not melt but decompose upon heating [39]. This fact limited his efforts to get stable polymers that show LC properties in the melt. It took several years until the problem with decomposition before melting in LCP (liquid crystal polymer) was solved by using random copolymers. Poly (g-benyl-L-glutamate) is the first lyotropic LC polymer, which was synthesized in 1950. Its pioneering work was achieved by Conmer Robinson in the 1950's. He studied solutions of poly-a-benzyl-L-glutamate and polya-benzyl-D-glutamate in various solvents and observed that below a limiting concentration which he called $A$, the solution is isotropic. Above this concentration two phases exist in equilibrium: namely, a polymer-rich phase (highly birefringent and brilliantly colored when viewed between crossed polars) and the more dilute isotropic phase. At a concentration greater than $B$ the anisotropic phase only exists. The values of $A$ and $B$ are dependent on the type of solvent together with the temperature, degree of polymerization of the polymer [40]. Among lyotropics another class of LCPs are rigid-rod polymers, where the polymer backbone is in a stretched, more, or less rigid, conformation. This class is mainly known for natural occurring polymers chitosan [41-43] or DNA [44, 45]. Its phase behavior is 
mainly dependent on the concentration in the case of lyotropic, but temperature plays a significant role, too.

\subsection{Cellulose-Based Liquid Crystal}

In 1956, Flory forecasted that polymers with stiff linear chains would form ordered phases in their respective melt and in concentrated solutions [46]. This behavior was reported for cellulose derivatives, such as hydroxypropyl cellulose (HPC) in water. At high concentration, it can reflect visible light due to its chiral nematic structure. HPC was the first cellulosic derivative reported to form spontaneous anisotropic solutions when dissolved in aqueous and organic solvents [47]. Since that discovery, other cellulose derivatives, e.g., cellulose acetate and triacetate, acetoxy propyl cellulose, methyl cellulose, ethyl cellulose, (acetyl)(ethyl)cellulose ethyl (cyano ethyl cellulose) and cellulose itself have also been reported to form ordered solutions [48-52].

The literature shows that polar or acidic solvents promote the formation of the mesophase for cellulose solutions. Highly substituted cellulose with large substituents preferentially forms nematic phases in many solvents [e.g. (acetoxypropy1)cellulose in different solvents of dialkyl phthalate]. Cellulose derivatives with low DS values or small substituents need specific solvent interaction in order to form such mesophases [52, 53]. The special conformation of cellulose considers a double-edged weapon as it has advantages and disadvantages for the preparation of liquid crystalline derivatives. The advantage results from the already stretched shape of the backbone which is a good starting point for LC properties due to its chirality and the synthesis of derivatives with high persistence lengths. But the high number of hydrogen bonds restricts the possible solvents for synthesis and leads to a high crystallinity of cellulose.

In 1976 Werbowyj and Gray found that concentrated solutions of HPC in water have a cholesteric liquid crystalline phase. They demonstrated that $20-50 \%$ water solution of HPC (molecular weight 100.000 and molar substitution 4.0 were highly iridescent and birefringent. They also reported that HPC can form ordered liquid crystal mesophase with cholesteric structure in concentrated solutions of polar organic solvents, e.g., methanol and ethanol [47, 54, 55]. HPC is able to form the two types of liquid crystal (lyotropic and thermotropic mesophases) [54, 56].

Cellulose derivatives, especially ethyl cellulose (EC) and hydroxypropyl cellulose (HPC), with structure in Figure 4, are readily capable of forming a cholesteric type of liquid-crystalline phase in a variety of common solvents such as acetic acid, $\mathrm{N}, \mathrm{N}$ dimethyl acetamide, $\mathrm{H}_{2} \mathrm{O}$, and dichloro acetic acid due to some degree of rigidity and achiral nature in the molecular structure [57].

The formation of the LC phase is dependent on polymer concentration, solvent type, and temperature. Increasing the solvent acidity led to an increase in the intrinsic viscosity and a decrease in the critical volume fraction (critical concentration decreases) [58, 59]. These observations are related to solvent interaction that greatly affects the flexibility of the polymer chain. The same behavior is noted for cellulose acetate solutions, where volume fraction is dependent on the acidity of solvent, and it varies linearly with pk of solvent [60].

With regard to HPC films from casting its water solutions, assume a planar cholesteric arrangement, with pitches in the range $100-200 \mathrm{~nm}$, based on the casting conditions. The cholesteric order in the cast films is persistent at room temperature and the behavior of the optical properties observed on heating are consistent with dynamic mechanical measurements, which reveal an increase in the molecular mobility above $120{ }^{\circ} \mathrm{C}$ [61-63]. Moreover, the physical packing (chiral arrangement) schemes of stiff cellulose chains could be considered for playing

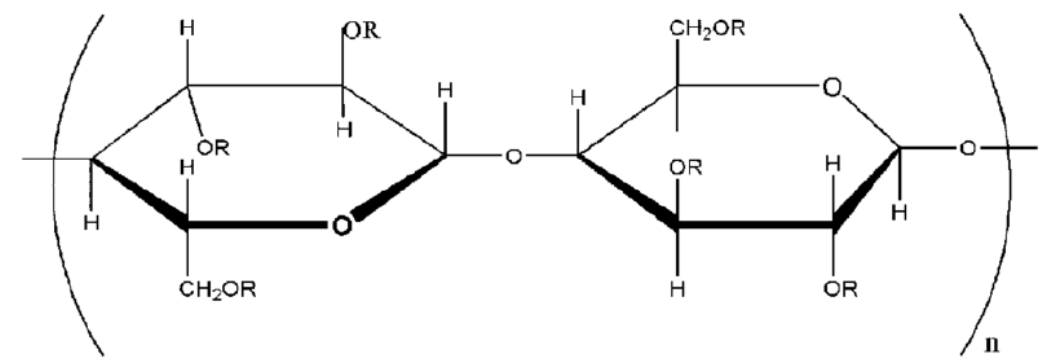

Figure 4: structure of Ethyl cellulose and hydroxy propyl cellulose. $\mathrm{R}$ : $\mathrm{H}$ or $\mathrm{CH}_{2} \mathrm{CH}_{3}$ for $\mathrm{EC}$ or $\mathrm{CH}_{2} \mathrm{CH}(\mathrm{OH}) \mathrm{CH}_{3}$ for $\mathrm{HPC}$. 
important roles in the formation of cholesteric LC phases. Particularly, when the flexible side chains are connected onto the cellulose backbones, the producing hairy-rod cellulose polymers start forming these cholesteric LC phases. It is believed that the attachment of flexible side chains onto the rigid cellulose molecules can facilitate the orientational order of the semi-rigid hairy-rod backbones with side chains, increasing chain mobility and enhancing solubility.

Among the cellulose derivatives, (2-hydroxypropyl) cellulose and other fully substituted cellulose derivatives are of specific interest because they can form cholesteric thermotropic LC phases [64, 65]. Cross-linked networks displaying both thermotropic and lyotropic liquid crystalline phases have been prepared from HPC. The phase transitions from the liquid crystal to the isotropic state are reversible for materials with moderate levels of crosslinking. These materials show characteristic optical textures similar to un-crosslinked cellulose-based liquid crystal polymers although welldefined patterns typical of cholesteric structures were not observed [66, 67]. The esterification of HPC by a series of aliphatic acid esters exhibited characteristic features of cholesteric LC phases between their glass transition and isotropization temperatures $[68,69]$. This literature confirmed that an increase in the number of methylene units in the side chains of this series of aliphatic acid esters of (2-hydroxypropyl) cellulose, led to an increase in the layer spacing values for the cholesteric LC phases measured by WAXD.

\subsubsection{Nanotechnology-Based Liquid Crystal Materials}

Recently, nanotechnology is used to develop biopolymer composites, via the addition of nanoparticles, it has opened new possibilities for improving their mechanical properties [70-72], Notably, the mechanical properties of polymeric matrices are increased to a large degree even for low CNCs contents (typically $1-10 \mathrm{wt} \%$ ) $[73,74]$.

Many approaches reported to extract cellulose nanoparticles such as mechanical treatment, acid hydrolysis [75,76], TEMPO-mediated oxidation [77,78], enzymatic hydrolysis [79, 80], sono-chemical assisted hydrolysis [81, 82] and ammonium persulfate oxidation that produces functionalized nano-particles with carboxylate group [83, 84]. Cellulose fibers can be disintegrated into substructures by strong acid hydrolysis. When cellulose is treated with strong acids, the amorphous regions of cellulose microfibrils are preferentially attacked and the resulting material is a colloidal suspension of cellulose crystallites. Strong acid hydrolysis of cellulose fibers, extracts the highly crystalline parts, resulting in rod-like crystallites of colloidal dimension named cellulose nanocrystals (CNC) or nanocrystalline cellulose (NCC) [85, 86]. Hydrochloric acid has also been used in hydrolysis, resulting in nanocrystals with no surface charge, which therefore tend to aggregate [87-89]. These cellulose nanocrystals (CNC) are shorter and stiffer than the native microfibrils and are sometimes referred to as whiskers or nano-rods. Hydrolysis with sulphuric acid is commonly used, and this results in particles with anionic sulfur ester groups on the surfaces, which leads to electrostatically stabilized CNC aqueous suspensions [90-92].

The hydrolysis conditions and cellulose source affect the surface chemistry and particle size of isolated cellulose nanocrystals. Sulfuric acid hydrolysis results in CNC particles with anionic sulfur groups on the surface, leading to electrostatically stabilized CNC aqueous suspensions of CNC [86, 91, 93, 94]. The researchers found that $\mathrm{CNC}$ aqueous suspensions exhibit chiral nematic (cholesteric) ordering above a critical concentration, these cellulose- nanoparticles can form a birefringent gel at even higher concentrations $[90,95,96]$. The formation and characteristics of chiral nematic ordered domains in CNC aqueous suspensions is generally governed by basic properties of the nanoparticles, namely, physical dimension, size polydispersity, surface charge and the ionic strength of the system [97-101].

Leung et al. in 2011 was the first one who used salts such as ammonium persulfate APS for the production of oxidized nanocellulose. Since 2011, the APS method has become widely used for obtaining CNC from different precursors such as cotton linter and other materials [102]. The APS mechanism includes that the persulfate ion $\mathrm{S}_{2} \mathrm{O}_{8}^{-2}$ can be activated using heat or light, and the resulting $\mathrm{SO}_{4}^{-}$radical initiates a chain of reactions involving other radicals and oxidants [103].

By using ammonium persulfate there is a one-step procedure for producing high crystalline carboxylated CNC (OCNC) from different cellulosic materials described. Currently, APS oxidation is reported as one of the promising oxidation methods to produce OCNC. Most of the literature is focused on the production of carboxylated $\mathrm{CNC}$ by heating the cellulose materials at $60-90{ }^{\circ} \mathrm{C}$ with $1-1.5 \mathrm{M}$ APS solution for 8-24 h. These conditions resulted in OCNC with a diameter of 3-100 
$\mathrm{nm}$ and a length between 100 and $500 \mathrm{~nm}$. APS oxidation has the potential to be used for OCNC production as an alternative to TEMPO-mediated oxidation. The nanocrystal suspensions prepared by persulfate oxidation also form chiral nematic ordered phases in water. Polarized light microscopy proved that suspensions of carboxylate cellulose nanocrystals, prepared from cotton and wood cellulose by oxidation with APS, form chiral nematic liquid crystalline phases at a concentration above a critical concentration [104, 105]. Besides CNC and OCNC there are other cellulose nanomaterials such as micro fibrillated cellulose (MFC) and cellulose nano-fibrils (CNF). MFC is produced through homogenization process of wood pulp fiber [106] and CNF is produced by a combination of enzymatic or chemical pretreatment followed by mechanical disintegration of cellulosic fibers [107] These cellulose nanomaterials have a longer length, less crystallinity, and thus more flexibility (lower rigidity), therefore their properties differ greatly from those of CNC and OCNC suspensions. MFC and CNF suspensions consist of interconnected cellulose fibrils and form a gel-like, highly viscous network at very low concentrations (i.e., 2 wt.\% aqueous suspensions). The formation of anisotropic liquid crystalline phases is also a unique characteristic of CNC, which does not occur in the case of other cellulosic nanostructures_(MFC and $\mathrm{CNF}$ ).

\section{CHARACTERIZATION OF THE LIQUID CRYSTAL MATERIALS}

Identification of the liquid crystal state can be made by evidencing the state of ordering through polarized optical microscopy (POM), X-ray diffraction (XRD), as well as phase transitions through differential scanning calorimetry (DSC) and rheological measurements.

\subsection{Polarized Optical Microscopy (POM)}

Polarized optical microscopy (POM) is the easiest method to identify thermotropic liquid crystals [108, 109 ] by recording an image known as the optical texture, due to the orientation of the director and defects formed in the sample. The area over which the vector abruptly changes direction represents a defect. The liquid crystals present three elementary types (point, line, and plane), and two major types (disclination and dislocation) of defects. For each type of mesophase, several, more or less characteristic, textures are known [110, 111]. Identification of mesophase type by POM is difficult because the same type of texture may appear for several mesophases, along with polymorphism. For this reason, a number of specific rules should be observed. First, to produce mesophase and to obtain clear textures, the sample must have a high degree of purity. Another aspect refers to the orientation of mesogenic groups, which may be parallel (homeotropic alignment) or vertical (planar alignment) in the direction of polarized light. In this last case, the following tests are required: mild heating of the table tilts so that the mesogenic groups will not be parallel with the polarized light or shearing of the sample (by sliding the upper blade on the bottom), which induces a temporarily homogeneous arrangement overtime in which the sample appears as a flash, for a short time becoming birefringent [110].

Identification of the nematic mesophase through POM is easier than that of the smectic mesophase because specific defects take a linear form. The nematic mesophase is characterized by a large number of textures: Schilieren texture is one of the most common nematic textures with defect centers with two arms, nematic droplets often occur from the isotropic liquid in the form of drops, string texture consists of a disclination type-line and appears as thin lines, and marble texture consists of several zones with different orientations of the director, inducing different color interferences [112]. Regarding the phase transition versus temperature, Ohledorf and Greine [113] reported that, the thermotropic liquid crystal of esterified HPC (methylthio- propionated HPC (HPCMTP) was observed in cholesteric and nematic phases. The phase transition from cholesteric to nematic was observed with changing the temperature from $25^{\circ} \mathrm{C}$ to $>70^{\circ} \mathrm{C}$, as shown in Figure 5.

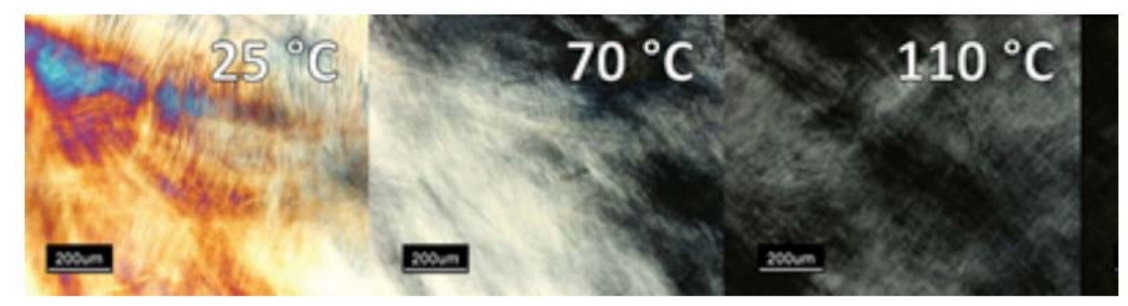

Figure 5: Polarized microscopy images of thermotropic liquid crystal of esterified at different temperatures. 


\subsection{X-Ray Diffraction (XRD)}

XRD is a nondestructive, versatile, and efficient technique, which offers information about the chemical composition and crystallographic structure of materials. It is used for the determination of the structural properties (deformation state, sizes, phase composition, orientation, and defects), the thickness of thin films or multilayers, or the atomic arrangement of the amorphous material. X-ray diffraction provides the most complete and accurate information on the type of mesophase ordering $[114,115]$. The signals obtained from X-ray diffraction give information about the ordering degree of the system, preferential directions of ordering, and details on the types of crystal structure occurring in the system.

\subsection{Differential Scanning Calorimetry (DSC)}

DSC is a thermal method commonly used to determine the liquid crystal phase transition during heating and cooling of a sample at a controlled rate [112]. The DSC method measures the flux between the sample and a reference (an inert material - aluminium oxide, gold, etc.) subjected to the same (isothermal and dynamic) temperature program.

The mesophase type cannot be precisely elucidated by the DSC thermogram, however, the thermal effect size and position signals recorded with this method provide information on mesophase identification and phase transitions.

\subsection{Rheological Measurements}

Rheological measurements are to support the optical and differential scanning calorimetry experiments on mesomorphic cellulose derivative solutions through the determination of the critical concentration [116].

The change in viscosity in the isotropic and anisotropic phases enables us to observe the transition [117]. The plot of the viscosity " $\eta$ " vs polymer concentration $C$ shows the peak characteristic of lyotropic polymer solutions. The viscosity first increases with concentration " $C$ " up to a critical concentration corresponding to the appearance of the anisotropic phase, also observed in optical microscopy between crossed polarizers. After this concentration, there is a competition between orders due to the shear and packing of the molecules in solution. The viscosity first decreases as shear ordering dominates. It then increases as packing effects become important.
Also, critical concentration can be determined through variation of $\mathrm{m}$ ( $\log \mathrm{T}$ vs. $\log \mathrm{D})$ with concentration. This gives a variation with the concentration of the power-law of eq. 3

$\tau=k D^{m}$

where $\tau$ is the shear stress (cp), $K$ constant $D$ shear rate $\left(\mathrm{s}^{-1}\right), \mathrm{m}$ strain rate sensitivity parameter.

In fact, when, $m=1$ (Newtonian behaviour), $m$ decreases linearly with concentration as the rheofluidifing character becomes evident until, at critical concentration, $\mathrm{rn}$ decreases drastically. A further increase of polymer concentration causes an increase of $\mathrm{m}$. This power-law can therefore be used to demonstrate the appearance of the anisotropic phase. The concentration range where $m$ decreases seem to correspond to the range where the drastic drop of the viscosity vs. concentration shows the appearance of an anisotropic phase [118-120].

\section{SYNERGISTIC EFFECT OF CELLULOSE-BASED NANOPARTICLES (CNPS) IN LIQUID CRYSTAL NANOCOMPOSITES}

The synergistic effects of cellulose nanoparticles towards better performances of liquid crystal nanocomposites are confirmed from our previously published articles [121, 122]. In this section, we present the liquid crystal behaviour of EC- and HPCnanocomposites due to incorporating $5 \% \mathrm{CNC}$ or OxCNF. The approaches of preparation of cellulose nanoparticles and their characterization were summarized in Table 1 and Figure $\mathbf{6}$. The synergistic effect was evaluated from measuring the critical concentration of liquid crystal behaviour (appearance of the anisotropic phase) via rheology and optical polarizing microscope studies.

\subsection{Rheology Study}

The rheology of cellulose ether (ethyl cellulose, EC and hydroxypropyl cellulose, HPC) and its composites with CNPs, at different concentrations, were examined by using acetic acid as solvent, with mechanical stirring for $\sim 20 \mathrm{~min}$, for homogenization.

The critical concentration which demonstrates the appearance of the anisotropic phase (m-value) is determined from the slope of the logarithms relation of shear stress to shear rate. [123]. Regarding the ethyl cellulose, Figure $7 \mathrm{a}$ showed the variation in critical concentration in the case of EC-CNPs composites compared with EC, individually. It is clear that the 


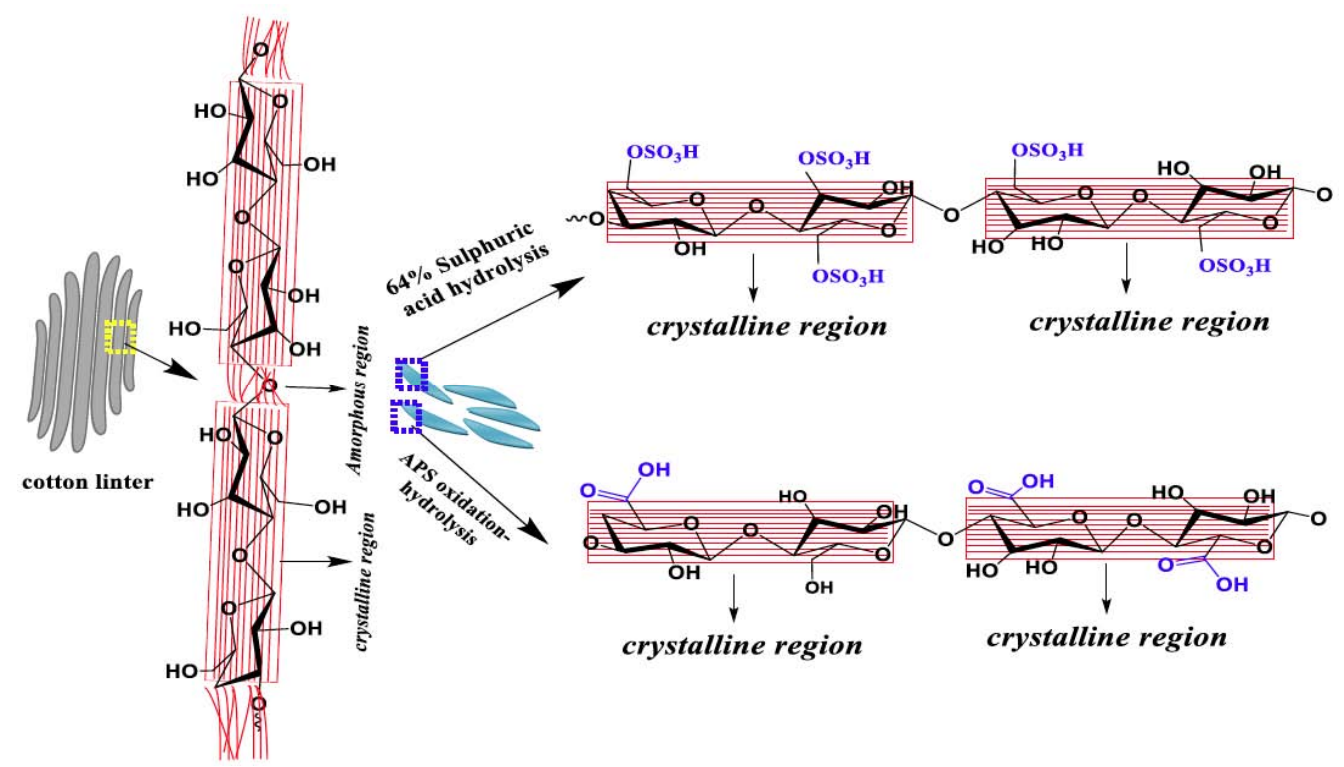

Figure 6: Schematic illustration of the preparation process of CNPs by sulphuric acid hydrolysis and APS oxidation-hydrolysis (Permission: Order License ID:1154412-1).

Table 1: Degree of Oxidation, FTIR, XRD and TEM Measurements of the Prepared Cellulose-Based Nanoparticles by Different Approaches (Permission: Order License ID:1154412-1)

\begin{tabular}{|c|c|c|c|c|c|c|c|c|c|}
\hline \multirow{2}{*}{\multicolumn{2}{|c|}{$\begin{array}{l}\text { CNPs based on two } \\
\text { methods of preparations }\end{array}$}} & \multirow{2}{*}{$\begin{array}{c}\text { Degree of } \\
\text { oxidation } \\
\text { (carboxyl } \\
\text { content) } \\
\text { by } \\
\text { conductmetric } \\
\text { mmol/g }\end{array}$} & \multirow{2}{*}{ 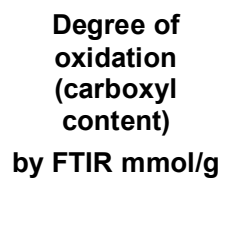 } & \multicolumn{2}{|c|}{ IR-measurements } & \multirow{2}{*}{$\begin{array}{l}\text { Cr. I. } \\
\text { (XRD) }\end{array}$} & \multicolumn{3}{|c|}{ TEM Measurements } \\
\hline & & & & MHBS & Cr. I. & & Length & Diameter & L/D \\
\hline C.L & & - & - & 2.18 & 1.78 & 70.39 & - & - & - \\
\hline \multirow{3}{*}{$\begin{array}{l}\text { In presence of } \\
\text { acid }\end{array}$} & APS $5 \mathrm{~h}$ & 0.066 & 0.080 & 2.26 & 2.84 & ---- & - & - & - \\
\hline & APS $8 \mathrm{~h}$ & 0.093 & 0.096 & 2.49 & 2.82 & 80.81 & $119 \pm 9$ & $13 \pm 6$ & 7.69 \\
\hline & $\begin{array}{l}\text { APS } \\
16 \mathrm{~h}\end{array}$ & 0.118 & 0.127 & 2.20 & 3.14 & 83.46 & $131 \pm 10$ & $8 \pm 2$ & 16.1 \\
\hline $\begin{array}{l}\text { In absence of } \\
\text { acid }\end{array}$ & $\begin{array}{l}\text { APS } \\
16 h^{*}\end{array}$ & 0.147 & 0.147 & 2.64 & 3.34 & 84.57 & $187 \pm 25$ & $6 \pm 2$ & 31.3 \\
\hline \multicolumn{2}{|c|}{ CNPs (sulphuric acid) } & - & - & 1.11 & 2.72 & 81.09 & $110 \pm 25$ & $4.3 \pm 1$ & 27.3 \\
\hline
\end{tabular}

m-value decreased linearly with increasing the concentration until a specific concentration corresponding to the critical concentration, then it increased with a further increase in concentration. The concentration which provided a maximum decrease in $m$ value referred to critical concentration to the appearance of an anisotropic phase. As shown, the critical concentration of ethyl cellulose is $40 \mathrm{wt}$ \%, in agreement with that reported in Reference [124]. While, incorporating cellulose nanoparticles led to a decrease in the critical concentration to (34- 38 wt.\%), with maximum promotion the performance of EC as liquid crystal and easily arranged both molecules of composite even at low concentrations. Was noticed in the case of EC-APS-16h^ nanocomposite.

In the same trend, incorporating the cellulose nanocrystal (CNC) and Oxidized cellulose nanofibers (OCNF (APS.16h*) provided a reduction in critical concentration (m-value) of HPC-NPS composites as compared with the pure HPC, where it decreased from $30 \mathrm{wt} \%$ to $26-28 \mathrm{wt} \%$, with the highest reduction in case of CNC (Figure $7 \mathbf{b}$ ).

APS 5h, APS $8 \mathrm{~h} \&$ APS 16h: $10 \mathrm{~g}$ of cotton was mixed with $114 \mathrm{~g}$ of APS, $20.5 \mathrm{ml}$ of $\mathrm{HCl}$ and distilled water to reach a final volume of $500 \mathrm{ml}$. 

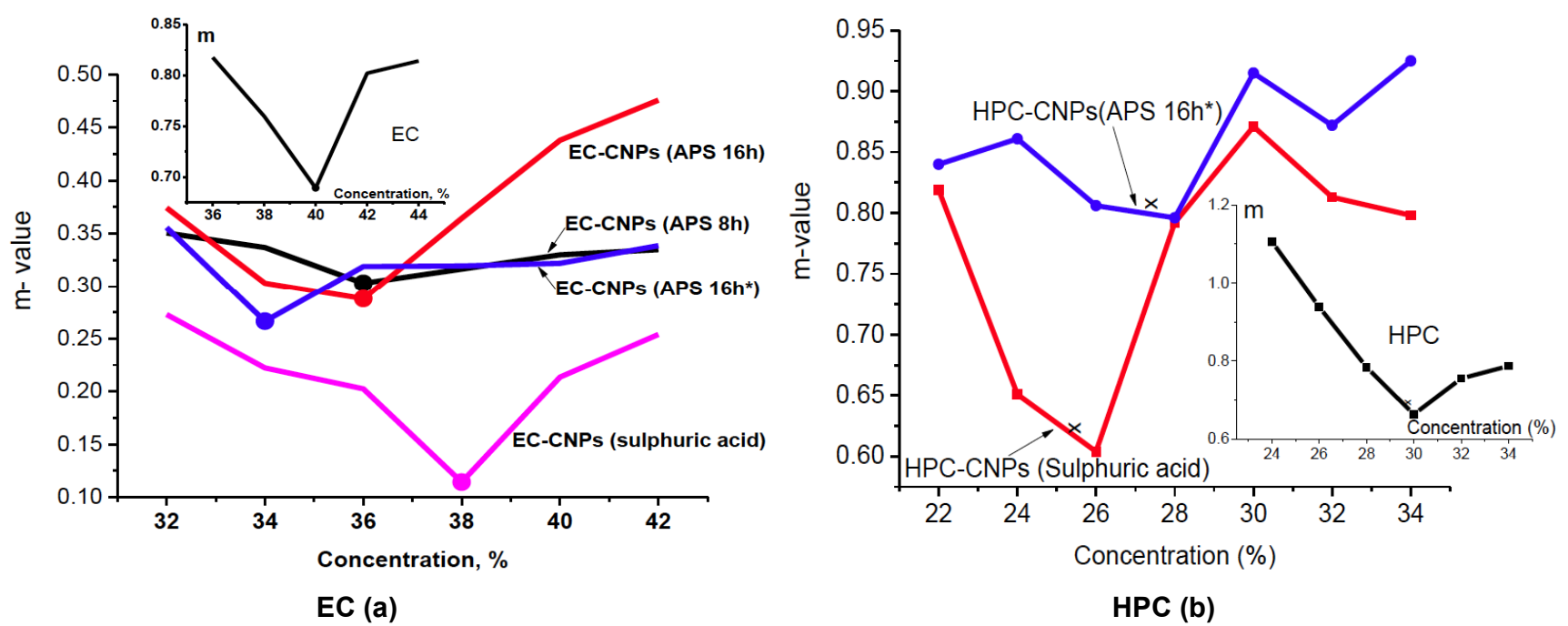

Figure 7: Variation of critical concentration vs type of cellulose nanoparticles.

The temperature of the reaction was adjusted to $90{ }^{\circ} \mathrm{C}$ for time intervals 5,8 and $16 \mathrm{~h}$ under continuous stirring. Then the solid was filtered and washed several times with distilled water. The sample was dried at $60^{\circ} \mathrm{C}$.

- $\quad$ APS $16 \mathrm{~h}^{*}: 10 \mathrm{gm}$ of cotton are added to the solution of $1 \mathrm{M}$ of APS with ratio $10: 1 \mathrm{~g} / \mathrm{L}$ (fibers/APS) at $90{ }^{\circ} \mathrm{C}$ for $16 \mathrm{~h}$ under continuous stirring. The final product was collected and dialyzed against distilled water until the sample become neutral.

- $\quad$ CNPs: The cotton linter was hydrolyzed by $64 \%$ $(\mathrm{w} / \mathrm{w})$ sulfuric acid according to reference, under conditions: liquor ratio $(1: 20)$ at $60^{\circ} \mathrm{C}$ for $30 \mathrm{~min}$, Finally, the sample was collected and dialyzed against distilled water until it becomes neutral.

\subsection{Polarizing Optical Microscope (POM)}

The POM study was carried out to evidence the positive role of CNPs on LC behaviour of EC and HPC in nanocomposite form. The same test was carried out individually (Figure $\mathbf{8 a}$ and $\mathbf{b}$ ). The examined samples were carried out on samples with concentrations around the critical concentrations, which were estimated from the foregoing study (rheology data). The images of the selected samples, at critical concentrations, under the polarized light, were exhibited bright with some dots or light areas. The lighted parts become full-colour textures with concentrations greater than a critical one. The anisotropic phase for the EC was started to appear at 40 wt \%, moreover, it appeared with chiral nematic liquid crystalline mesophases at concentrations greater than $40 \mathrm{wt} . \%$. The beneficial; effect of incorporating CNPs was noticed from appearing the anisotropic phase at lower concentrations, which changed according to the method of preparation, where the critical concentration in case of $\mathrm{CNC}$ and OCNF (APS16h*) were 34 wt. $\%$ and 38 wt $\%$, respectively. While the chiral nematic mesophases appeared at a greater concentration than critical concentration.

With regard to POM of HEC and its nanocomposites, Figure $\mathbf{8 b}$ showed that the isotropic regions must be black, while the birefringent regions must be bright. These images emphasized the critical concentration data of the rheological study (HPC-CNC and HPC-OCNP in acetic acid were $26 \mathrm{wt}$. \% and $28 \mathrm{wt}$. $\%$, respectively). The POM of HPC-CNPs at a critical concentration of HPC $(30 \%)$, Figure $5 \mathbf{b}$ showed that at this concentration (> critical concentration), the ordered texture images appeared with coloured parts.

\section{CONCLUSION}

Cellulose-based materials have been applied in a variety of applications and their nanoparticles have a significant effect in optical, strength properties. This article is a Literature survey with comprehensive research work of liquid crystal materials, and provides information regarding the inclusion of cellulose derivatives, especially cellulose ethers (ethyl cellulose and hydroxypropyl cellulose) as important types of research work. Moreover, we presented how the type of cellulose nanoparticles affected the performance of EC and HPC as liquid crystal materials via reducing the critical concentration of the anisotropic phase. The optical microscopy examination is in agreement with rheology. 


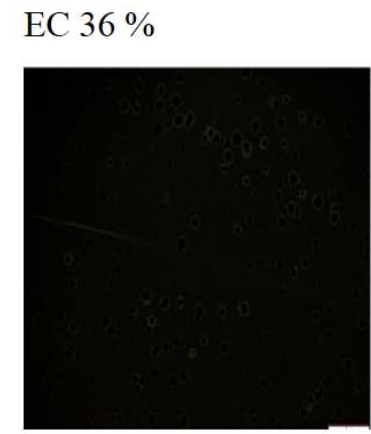

EC-NCC 34\%

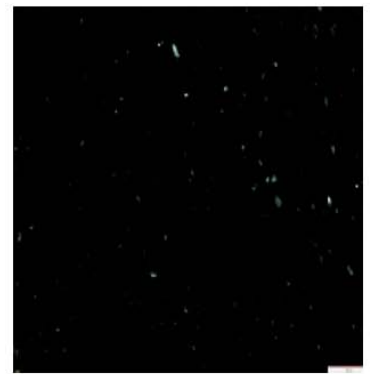

EC-APS. $16 h^{*} 34 \%$
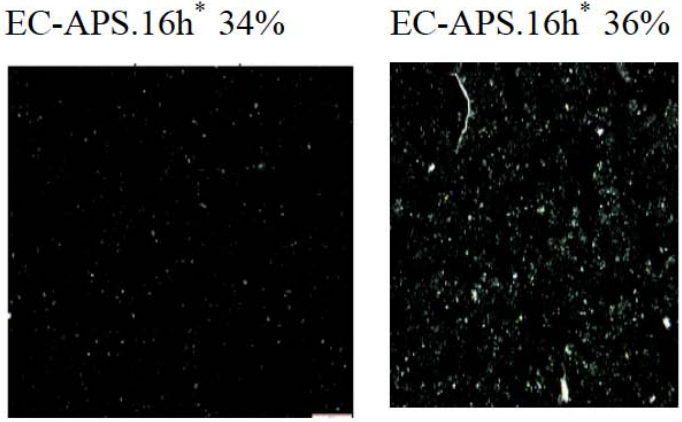

EC-NCC $36 \%$

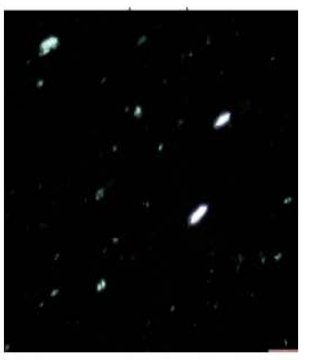

EC-NCC $38 \%$

a

HPC $30 \%$

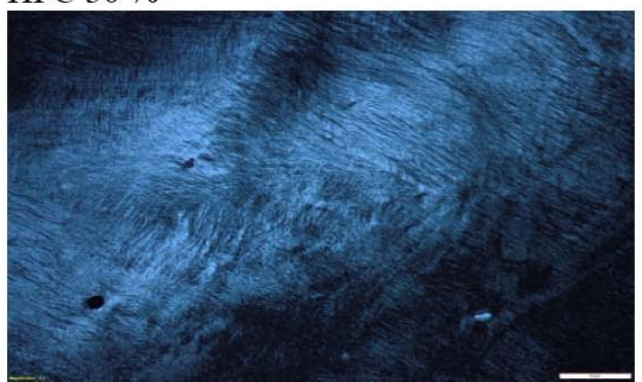

HPC-CNC 26 wt.\%

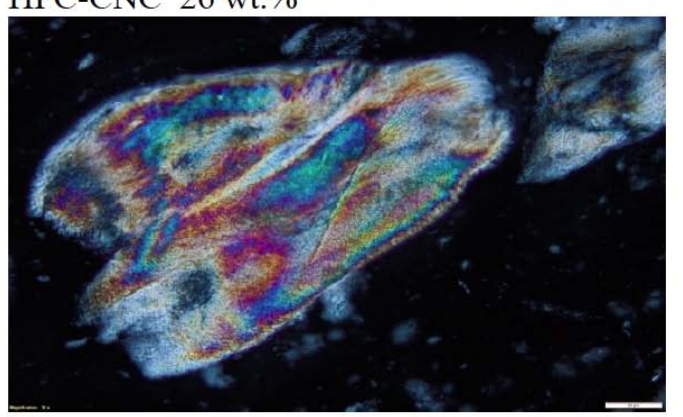

EC $42 \%$
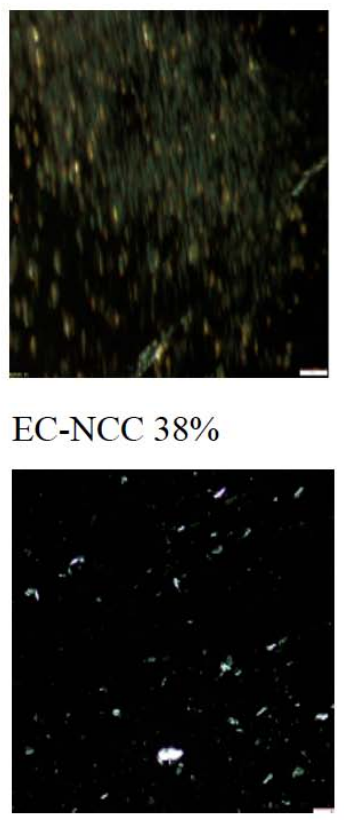

EC-APS. $16 h^{*} 38 \%$

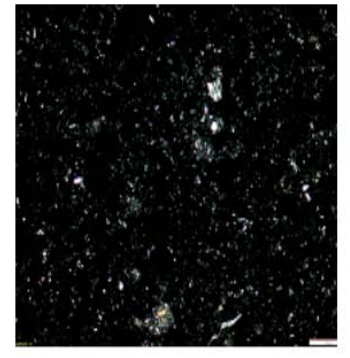

EC-APS. $16 h^{*} 42 \%$

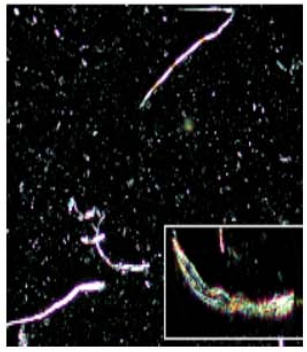

EC $44 \%$

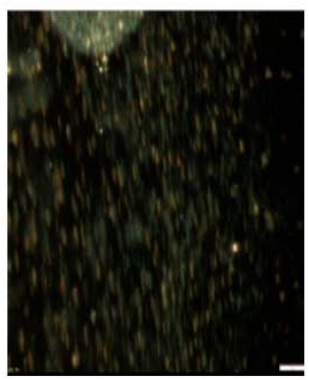

EC-NCC 42\%

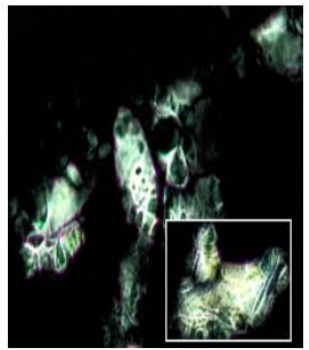

HPC-CNC $30 \%$

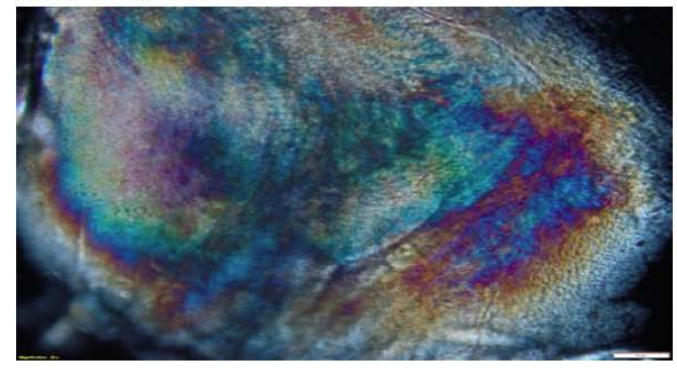

HPC-CNC 24wt.\%

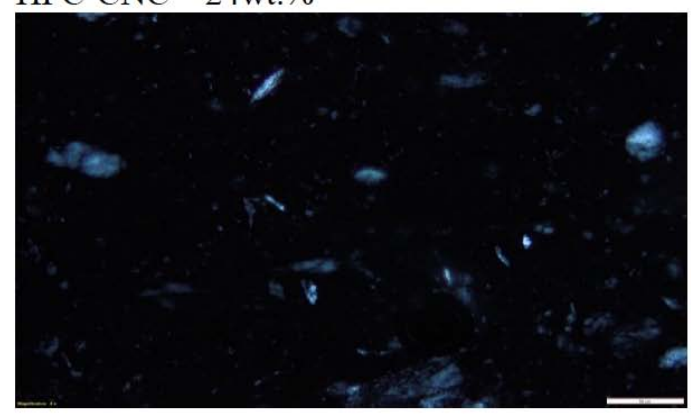



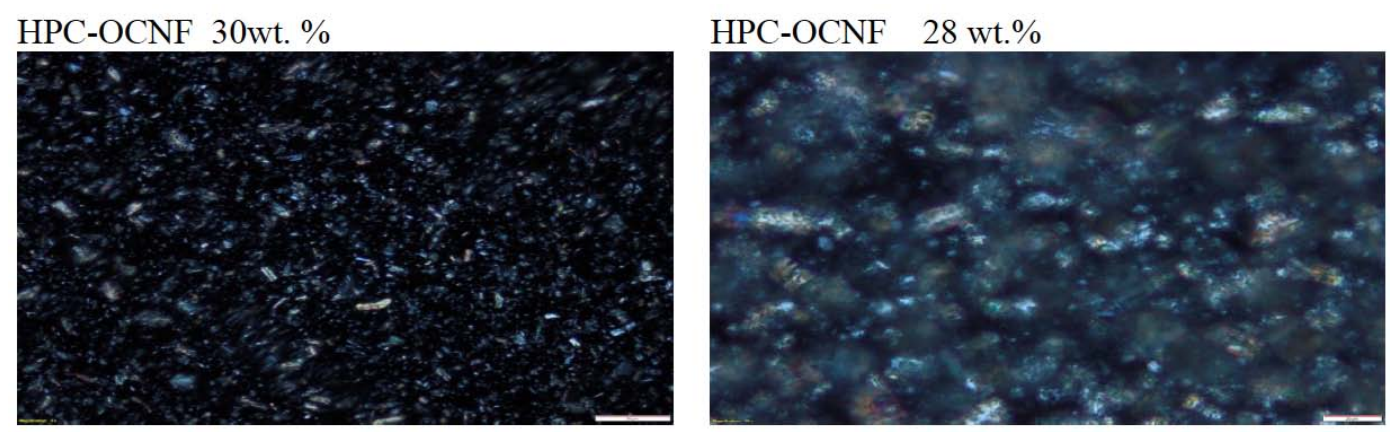

HPC-OCNF 26wt. \%

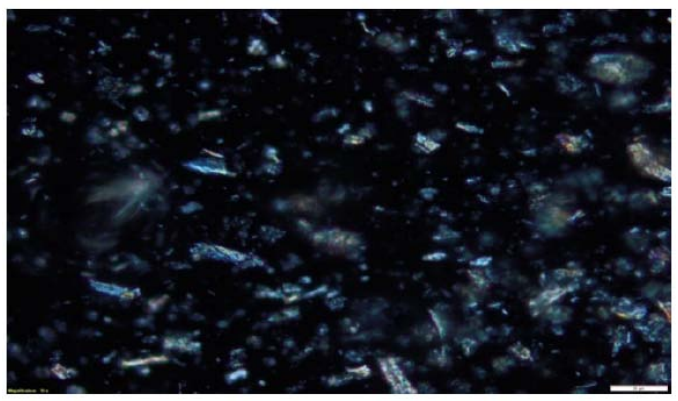

b

Figure 8a: PO images of EC and its nanocomposites with cellulose nanoparticles. (permission, License Number:5163760664250).

b: POM images of HPC and its nanocomposites with cellulose nanoparticles (permission: Order License ID:1154412-1).

\section{ACKNOWLEDGEMENT}

The authors acknowledged the National Research Centre, Egypt. for providing financial support and providing necessary lab facilities for work dealing with the synergistic effect of Cellulose-NPs in enhancing the performance of HPC \& EC as liquid crystal materials (delivered from Ms. Thesis)

\section{CONFLICTS OF INTEREST}

The corresponding author on behalf of co-authors declare no conflict of interest. We reported the permission (License numbers) via Copyright Clearance Centre, for Table and Figures from our previous published articles.

\section{REFERENCES}

[1] Lavanya D, Kulkarni P, Dixit M, Raavi PK, Krishna LNV. Source of cellulose derivatives and their applications. Int $\mathrm{J}$ Drug Form Res 2011; 2: 19-38.

[2] Hu J, Chen S, A review of actively moving polymers in textile applications. J Mater Chem 2010; 20(17): 3346-3355. https://doi.org/10.1039/b922872a

[3] Thakur, VK; Thakur MK, Gupta RK. Development of functionalized cellulosic biopolymers by graft copolymerization. Int J Biol Macromol 2013; 62: 44-51. https://doi.org/10.1016/j.ijbiomac.2013.08.026
[4] Basta AH, El-Saied H, Lotfy VF. Performance assessment of deashed and dewaxed rice straw on improving the quality of RS-based composites. RSC Adv 2013; 4 (42): 21794-21801. https://doi.org/10.1039/C4RA00858H

[5] Basta $\mathrm{AH}$, Khwaldia K, Aloui H, El-Saied H. Enhancing the performance of carboxymethyl cellulose by chitosan in producing barrier coated paper sheets. Nordic Pulp Paper Res J 2015; 30 (4): 617-625. https://doi.org/10.3183/npprj-2015-30-04-p617-625

[6] Cerchiara T, Abruzzo A, Parolin C et al. Microparticles based chitosan/ carboxymethylcellulose polyelectrolyte complexes for colon delivery of vancomycin. Carbohydr Polym 2016; 43: 124-130. https://doi.org/10.1016/j.carbpol.2016.02.020

[7] Basta AH, El-Saied,H, Baraka AM, Lotfy VF. Performance of Carbon Xerogels in the Production of Environmentally Friendly Urea Formaldehyde-Bagasse Composites, CLEANSoil, Air, Water 2017; 45 (6): 1600524. https://doi.org/10.1002/clen.201600524

[8] Basta AH, Lotfy VF, Hasanin MS, Trens P, El-Saied H. Efficient treatment of rice byproducts for preparing highperformance activated carbons. J Clean Prod 2019; 207: 284-295. https://doi.org/10.1016/j.jclepro.2018.09.216

[9] Basta AH, Lotfy VF, Mahmoud K, Abdelwahed NAM. Synthesis and evaluation of protein-based biopolymer in production of silver nanoparticles as bioactive compound versus carbohydrates-based biopolymers. Royal Soc Open Sci 2020; 7 (10): 200928. https://doi.org/10.1098/rsos.200928

[10] Yang S, Wu X, Wang X, Samuelson LA, Cholli AL, Kumar J. Synthesis and Characterization of Fluorescent Cellulose. J Macromol Sci, Part A 2003; 40: 1275-1282. https://doi.org/10.1081/MA-120025307 
[11] Boerstoel H, Maatman H, Westerink JB, Koenders BM. liquid crystalline solutions of cellulose in phosphoric acid. J polymer 2001; 42: 7371-7379.

https://doi.org/10.1016/S0032-3861(01)00210-5

[12] lizuka E. Properties of liquid crystal of some polymers. J Adv Biophys 1988; 42: 1-56. https://doi.org/10.1016/0065-227X(88)90003-2

[13] de Gennes PG. Prost J The Physics of Liquid Crystals, 2nd edition ed., Clarendon Press 1995. https://doi.org/10.1063/1.2808028

[14] Song J, Liu F, Han YY, Zheng YB, Preparation of cellulose liquid crystal solution and its application. J Tianjin Polytech Univ 2017; 36: 27-30.

[15] Huang B, Ge JJ, Li Y, Hou H. Aliphatic acid esters of (2hydroxypropyl)cellulose-Effect of side chain length on properties of cholesteric liquid crystals. J Polymer 2007; 48: 264-269.

https://doi.org/10.1016/j.polymer.2006.11.033

[16] Godinho MH, Gray DG, Pieranski P. Revisiting (hydroxypropyl) cellulose (HPC)/water liquid crystalline system. J Liquid Crystal 2017; 44: 1-13.

https://doi.org/10.1080/02678292.2017.1325018

[17] Tomizawa A, Mori $Y$, Kasuya N. Synthesis of novel and regioselectively mesogen-incorporated thermotropic liquid crystals from cellulose derivatives. J of Macromolecular Science, Part A 2017; 54: 860-866. https://doi.org/10.1080/10601325.2017.1339561

[18] Fukawa M, Suzuki K, Furum S. Disappearance of reflection color by Photo- polymerization of lyotropic cholesteric liquid Crystals from Cellulose Derivatives. J Photopolym Sci and Technol 2018; 31: 563-567. https://doi.org/10.2494/photopolymer.31.563

[19] Vshivkov SA, Rusinova E. Effect of Component Nature on Liquid-Crystalline Transitions in Solutions of Cellulose Ethers. J Polymer Sci 2018; 60: 65-73. https://doi.org/10.1134/S0965545X18010078

[20] Chandrasekhar S, Sadashiva BK, Suresh KA. Liquid crystals of disc-like molecules. Pramana 1977; 9 (5): 471-480. https://doi.org/10.1007/BF02846252

[21] Demus D, Stegemeyer H (Ed.), Topics in Physica Chemistry: Liquid Crystals. Steinkopff Verlag, Darmstadt, 1994.

[22] Pelzl G, Diele S, Weissflog W. Banana-Shaped Compounds A New Field of Liquid Crystals. Adv Mater 1999; 11 (9): 707724.

https://doi.org/10.1002/(SICl)15214095(199906)11:9<707::AID-ADMA707>3.0.CO;2-D

[23] Zimmermann H, Poupko R, Luz Z, Billard J. Pyramidic mesophases. Zeitschrift fur Naturforschung Section a - J Phys Sci 1985; 40 (2): 149-160.

https://doi.org/10.1515/zna-1985-0208

[24] Matsuo Y. C60 Derivatives Having Self-Assembly Capabilities. Fuller. Nanotub. Carbon Nanostr 1985; 18 (4-6): 338-352.

https://doi.org/10.1080/1536383X.2010.487395

[25] Donald AM, Windle AH, Hanna S. Liquid Crystalline Polymers 2nd Edition. Cambridge University Press, Cambridge, 2006.

https://doi.org/10.1017/CBO9780511616044

[26] Shibaev V. Liquid Crystalline Polymers. In: Saleem Hashmi (editor-in-chief), Reference Module in Materials Science and Materials Engineering. Oxford: Elsevier 2016; pp. 1-46. https://doi.org/10.1016/B978-0-12-803581-8.01301-1

[27] Dierking I, Al-Zangana S. Lyotropic liquid crystal phases from anisotropic nanomaterials. Nanomater 2017; 7: 305 (1-27). https://doi.org/10.3390/nano7100305

[28] Friberg S. Lyotropic Liquid-Crystals - Preface. Adv Chem Ser 1976; R7-R7.

https://doi.org/10.1021/ba-1976-0152
[29] Petrov AG. Liquid crystal physics and the physics of living matter. Mol Cryst Liq Cryst 1999; 332: 3087-3094. https://doi.org/10.1080/10587259908023804

[30] Collings PJ, Hird, M. Introduction to liquid crystals chemistry and physics. Taylor \& Francis: London; Bristol, PA, p xi, 1997; p. 298.

https://doi.org/10.4324/9780203211199

[31] Kosa T, Sukhomlinova L, Su L, Taheri B, White TJ, Bunning TJ. Light-induced liquid crystallinity. Nature 2012; 485 (7398): 347-349.

https://doi.org/10.1038/nature11122

[32] Dierking I. Chiral liquid crystal: Structures, Phases, Effects. Symmetry 2014; 6: 444-472. https://doi.org/10.3390/sym6020444

[33] Shibaev PV, Chiappetta D, Sanford RL, Palffy-Muhoray P Moreira M, Cao W, Green MM. Color Changing Cholesteric Polymer Films Sensitive to Amino Acids. Macromol 2006; 39 (12): 3986-3992. https://doi.org/10.1021/ma052046o

[34] Choi SS, Morris SM, Huck WTS, Coles HJ. The switching properties of chiral nematic liquid crystals using electrically commanded surfaces. Soft Matter 2009; 5 (2): 354-362. https://doi.org/10.1039/B810691F

[35] Doganci E, Davarci D. Synthesized and mesomorphic properties of cholesterol end-cappedpoly( $\varepsilon$-caprolactone) polymers. J Polym Res 2019; 26: 165. https://doi.org/10.1007/s10965-019-1826-1

[36] Miyagi K, Teramoto Y. Elucidation of the Mechanism of Stress-Induced Circular Dichroic Inversion of Cellulosic/Polymer Liquid Crystalline Composites. Macromol 2020; 53 (8): 3250-3254.

https://doi.org/10.1021/acs.macromol.9b02741

[37] Ghosh T, Lehmann M. Recent advances in heterocyclebased metal-free calamitics. J Mater Chem C 2017; 5: 12308-12337. https://doi.org/10.1039/C7TC03502K

[38] Wang X, Li Z, Zhao H, Chen S. New azobenzene liquid crystal with dihydropyrazole heterocycle and photoisomerization studies. Royal Soc Open Sci 2020; 7: 200474.

https://doi.org/10.1098/rsos.200474

[39] Bruce DW, Heyns K, Vill V. Vorlander's wheel. Liq Cryst 1997; 23 (6): 813-819. https://doi.org/10.1080/026782997207740

[40] Elliott A, Ambrose EJ. Evidence of chain folding in polypeptides and proteins. Discuss Faraday Soc 1950; 9 : 246-251. https://doi.org/10.1039/df9500900246

[41] Terbojevich M, Cosani A, Conio G, Marsano E, Bianchi E. Chitosan: chain rigidity and mesophase formation. Carbohydr Res1991; 209: 251-260.

https://doi.org/10.1016/0008-6215(91)80161-F

[42] Iftime MM, Irimiciuc SA, Agop M, Angheloiu M, Ochiuz L, Vasincu D. A theoretical multifractal model for assessing urea release from chitosan-based formulations. Polymers 2020; 12 (6): 1-13.

https://doi.org/10.3390/polym12061264

[43] Ailincai D, Marin L. Eco-friendly PDLC composites based on chitosan and cholesteryl acetate. J Mol Liq 2021; 321: 114466 (1-10). https://doi.org/10.1016/j.molliq.2020.114466

[44] Strzelecka TE, Davidson MW, Rill RL. Multiple Liquid Crystal Phases of DNA at High Concentrations. Nature 1988; 331(6155): 457-460. https://doi.org/10.1038/331457a0

[45] Hamley IW. Liquid crystal phase formation by biopolymers. Soft Matter 2010; 6 (9): 1863-1871. https://doi.org/10.1039/b923942a 
[46] Flory PJ, Gordan M, Plate NA (Eds). Advances in Polymer Science: Liquid Crystal Polymers I. Springer-Verlag, Berlin, 1984.

[47] Werbowyj RS, Gray DG. Liquid crystalline structure in aqueous hydroxypropyl cellulose solutions. Mol Cryst Liq Cryst 1976; 34: 97-103.

https://doi.org/10.1080/15421407608083894

[48] Boerstoel H, Maatman H, Picken SJ, Remmers R, Westerink JB. Liquid crystalline solutions of cellulose acetate in phosphoric acid. Polymer 2001; 42: 7363-7369. https://doi.org/10.1016/S0032-3861(01)00209-9

[49] Ritcey AM, Holme KR, Gray DG. Cholesteric Properties of Cellulose Acetate and Triacetate in Trifluoroacetic Acid. Macromol 1988; 21: 2914-2917. https://doi.org/10.1021/ma00188a003

[50] Yin Y, Nishinari K, Zhang H, Funami T. A Novel LiquidCrystalline Phase in Dilute Aqueous Solutions of Methyl cellulose. Macromol. Rapid Commun 2006; 27: 971-975. https://doi.org/10.1002/marc.200600099

[51] Wang L, Wang X, Huang Y. Optical Properties of EthylCyanoethyl Cellulose / Poly (acrylic acid) Cholesteric Liquid Crystalline Composite Films. Journal of Appl Polym Sci 2004; 92: 213-217.

https://doi.org/10.1002/app.13433

[52] Boerstoel H, Maatman H, Westerink JB, Koenders BM. Liquid crystalline solutions of cellulose in phosphoric acid. Polymer 2001; 42: 7371-7379. https://doi.org/10.1016/S0032-3861(01)00210-5

[53] Gray DG. Chiral nematic ordering of polysaccharides. Carbohydr Polym 1994; 25 (4): 277-284. https://doi.org/10.1016/0144-8617(94)90053-1

[54] Shimamura K. White JL, Fellers JF. Hydroxy propyl cellulose, a thermotropic liquid crystal: Characteristics and structure development in continuous extrusion and melt spinning. Appl Polym Sci 1981; 26: 2165-2180. https://doi.org/10.1002/app.1981.070260705

[55] Godinho MH, Gray DG, Pieranski P, Revisiting (hydroxypropyl) cellulose (HPC)/water liquid crystalline system. Liq Cryst 2017; 44(12): 1-13.

\section{https://doi.org/10.1080/02678292.2017.1325018}

[56] Zugenmaier P. In: Handbook of Liquid Crystals, D. Demus, J. Goodby GW, Gray HW, Spiess and V. Vill (eds.), Wiley-VCH, Weinheim, 1989; Vol. 3: pp. 453.

[57] Gilbert RD, Patton PA. Liquid crystal formation in cellulose and cellulose derivatives. Prog Polym Sci 1983; 9 (2-3): 115131.

https://doi.org/10.1016/0079-6700(83)90001-1

[58] Bheda J, Fellers J F, White JL, Phase behavior and structure of liquid crystalline solutions of cellulose derivatives. Colloid Polym Sci 1980; 258: 1335-1342. https://doi.org/10.1007/BF01668781

[59] Fukawa M, Kawaguchi A, Hayata K, Aoki R, Furukawa M, Furumi S. Syntheses, and properties of cellulosic derivatives for reflection color films. J Photopolym Sci Technol 2019; 32(4): 633-637.

https://doi.org/10.2494/photopolymer.32.633

[60] Aharoni SM. Rigid Backbone Polymers, XIII: Effects of the Nature of the Solvent on the Lyotropic Mesomorphicity of Cellulose Acetate. Mol Cryst Liq Cryst 1980; 56: 237-241. https://doi.org/10.1080/01406568008070497

[61] Charlet G, Gray DG. Solid Cholesteric Films Cast from Aqueous. Macromol 1987; 20 (1): 33-38. https://doi.org/10.1021/ma00167a007

[62] Chiba R, Nishio $Y$, Sato $Y$, Ohtaki M, Miyashita $Y$. Preparation of cholesteric (hydroxypropyl)cellulose/polymer networks and ion-mediated control of their optical properties. Biomacromol 2006; 7(11): 3076-3082. https://doi.org/10.1021/bm060567
[63] Zhang Q, Qian L, Wang L, Stuto S, Shen, C. Study of casting self-colored liquid crystalline solid films of hydroxy propyl cellulose. Appl Mechan Mater 2013; 341-342: 217-220. https://doi.org/10.4028/www.scientific.net/AMM.341-342.217

[64] Yamagishi T, Fukuda T, Miyamoto T, Watanabe J. Thermotropic cellulose derivatives with flexible substituents. II. Effect of substituents on thermal properties. Polym Bull 1988; 20 (4): 373-377. https://doi.org/10.1007/BF00255739

[65] Yamagishi T, Fukuda T, Miyamoto T, Yakoh Y, Takashina $Y$, Watanabe J. Thermotropic cellulose derivatives with flexible substituents. IV. Columnar liquid crystals from ester-type derivative of cellulose. Liq Cryst 1991; 10(4): 467-473. https://doi.org/10.1080/02678299108036436

[66] Mitchell GR, Guo W, Davis FJ. Liquid crystal elastomers based upon cellulose derivatives. Polymer 1992; 33 (1): 68-74. https://doi.org/10.1016/0032-3861(92)90561-A

[67] Ishii D, Ueda K, Stroeve P, Nakaoki T, Hayashi H. Transport Properties of Chemically Crosslinked Hydroxypropyl Cellulose in Solvated State. Cellul Chem Technol 2016; 50(7-8): 755-760.

[68] Huang B, Ge JJ, Li Y, Hou H. Aliphatic acid esters of (2hydroxypropyl) cellulose-Effect of side chain length on properties of cholesteric liquid crystals. Polymer 2007; 48 (1): 264-269. https://doi.org/10.1016/j.polymer.2006.11.033

[69] Hayata K, Furumi S. Side chain effect of hydroxypropyl cellulose derivatives on reflection properties. Polymers 2019; 11 (10): 1-8. https://doi.org/10.3390/polym11101696

[70] Bilbao-Sainz C, Bras J, Williams T, Sénechal T, Orts W. HPMC reinforced with different cellulose nano-particles. Carbohydr Polym 2011; 86 (4): 1549-1557. https://doi.org/10.1016/j.carbpol.2011.06.060

[71] Ma L, Wang L, Wu L, Zhuo D, Weng Z, Ren R. Cellulosic nano composite membranes from hydroxypropyl cellulose reinforced by cellulose nanocrystals. Cellulose 2014; 2 (6): 4443-4454.

https://doi.org/10.1007/s10570-014-0405-1

[72] Walters CM, Boott CE, Nguyen, T-D, Hamad WY MacLachlan MJ. Iridescent Cellulose Nanocrystal Films Modified with Hydroxypropyl Cellulose. Biomacromol 2020; 21: 1295-1302. https://doi.org/10.1021/acs.biomac.0c00056

[73] Moon RJ, Martini A, Nairn J, Youngblood J, Martini A, Nairn J. Cellulose nanomaterials review: structure, properties and nanocomposites. Chem Soc Rev 2011; 40: 3941-3994. https://doi.org/10.1039/c0cs00108b

[74] Nandi S, Guha P.A Review on Preparation and Properties of Cellulose Nanocrystal-Incorporated Natural Biopolymer. J Packag Technol Res 2018; 2 (2): 149-166. https://doi.org/10.1007/s41783-018-0036-3

[75] Khatoon N, Ramezani O, Kermanian $\mathrm{H}$. Production of Nanocrystalline Cellulose from Sugarcane Bagasse, 4th Int. Conf. Nanostr, 12-14, 2012.

[76] Arai K, Horikawa Y, Shikata T. Transport Properties of Commercial Cellulose Nanocrystals in Aqueous Suspension Prepared from Chemical Pulp via Sulfuric Acid Hydrolysis. J ACS Omega 2018; 3: 13944-13951. https://doi.org/10.1021/acsomega.8b01760

[77] Myja D, Loranger É, Lanouette R. TEMPO Mediated Oxidation Optimization on Thermo mechanical Pulp for Paper Reinforcement and Nanomaterial Film Production. BioResources 2018; 13 (2): 4075-4092. https://doi.org/10.15376/biores.13.2.4075-4092

[78] Deckers C, Linden M, Löwe H. Nitroxyl Radical-Mediated Oxidation of Alcohols in Continuous Microreactors. Chem Eng Techno 2019; 42 (10): 2044-2051. https://doi.org/10.1002/ceat.201800427 
[79] Zhu JY, Sabo R, Luo X. Integrated production of nanofibrillated cellulose and cellulosic biofuel (ethanol) by enzymatic fractionation of wood fibers. Green Chem 2011; 13: $1339-1344$.

\section{https://doi.org/10.1039/c1gc15103g}

[80] Ribeiro RSA Pohlmann BC, Calado V, Bojorge N, Pereira N. Production of nanocellulose by enzymatic hydrolysis: Trends and challenges. Eng Life Sci 2019; 19: 279-291. https://doi.org/10.1002/elsc.201800158

[81] Durán N, Lemes AP, Durán $M$, Freer J, Baeza J. A mini review of cellulose nanocrystals and its potential integration as co-product in bioethanol production. J Chil Chem Soc 2011; 56: 672-677.

https://doi.org/10.4067/S0717-97072011000200011

[82] Chen $Y$, Wu Q, Ai X, Huang M, Lu Q. Sono-chemical preparation of cellulose nanowhiskers from luffa cylindrica fibers optimized by response surface methodology. Cellul Chem Technol 2017; 51: 775-783.

[83] Mascheroni E, Rampazzo R, Ortenzi MA, Piva G, Bonetti S, Piergiovanni L. Comparison of cellulose nanocrystals obtained by sulfuric acid hydrolysis and ammonium persulfate, to be used as coating on flexible food-packaging materials. Cellulose 2016; 23: 779-793.

https://doi.org/10.1007/s10570-015-0853-2

[84] Filipova I, Fridrihsone V, Cabulis U, Berzins A. Synthesis of nanofibrillated cellulose by combined ammonium persulphate treatment with ultrasound and mechanical processing. Nanomater 2018; 8: 2-11. https://doi.org/10.3390/nano8090640

[85] Marchessault RH, Morehead FF, Koch MJ. Some hydrodynamic properties of neutral suspensions of cellulose crystallites as related to size and shape. J Colloid Sci 1961; 16: 327-344. https://doi.org/10.1016/0095-8522(61)90033-2

[86] Shafiei-Sabet S, Hamad WY, Hatzikiriakos SG. Influence of Degree of Sulfation on the Rheology of Cellulose Nanocrystal Suspensions. Rheol Acta 2013; 52: 741-751. https://doi.org/10.1007/s00397-013-0722-6

[87] Wagberg L, Winter L, Odberg L, Lindstom T. On the charge stoichiometry upon adsorption of a cationic polyelectrolyte on cellulosic materials. Colloids Surf 1987; 27: 163-173. https://doi.org/10.1016/0166-6622(87)80335-9

[88] Araki J, Wada M, Kuga S, Okano T. Flow properties of microcrystalline cellulose suspension prepared by acid treatment of native cellulose. Colloids and Surfaces, A: Physicochem Eng Aspects 1998; 142 (1): 75-82. https://doi.org/10.1016/S0927-7757(98)00404-X

[89] Araki J, Wada M, Kuga S, Okano T. Birefringent glassy phase of a cellulose microcrystal suspension. Langmuir 2000; 16 (6): 2413-2415. https://doi.org/10.1021/la9911180

[90] Revol JF, Bradford H, Giasson J, Marchessault RH, Gray DG. Helicoidal self-ordering of cellulose microfibrils in aqueous suspension. Int J Biolog Macromol 1992; 14: 170172. https://doi.org/10.1016/S0141-8130(05)80008-X

[91] Dong XM, Revol JF, Gray DG. Effect of microcrystallite preparation conditions on the formation of colloid crystals of cellulose. Cellulose 1998; 5: 19-32. https://doi.org/10.1023/A:1009260511939

[92] Morais JPS, Rosa MDF, De Souza Filho MDSM, Nascimento LD, Do Nascimento DM, Cassales AR. Extraction and characterization of nanocellulose structures from raw cotton linter. Carbohydr Polym 2013; 91: 229-235. https://doi.org/10.1016/j.carbpol.2012.08.010

[93] Canilha L, Chandel AK, Suzane Dos Santos Milessi T, Antunes FAF, Luiz Da Costa Freitas W, Das Graças Almeida Felipe M, Da Silva SS. Bioconversion of sugarcane biomass into ethanol: An overview about composition, pretreatment methods, detoxification of hydrolysates, enzymatic saccharification, and ethanol fermentation. J Biomed Biotechnol 2012; 2012, Article ID 989572 (1-15). https://doi.org/10.1155/2012/989572

[94] De Sousa MM, Vianna A, De Carvalho N, Silva DDJ. Cellulose Nanocrystal Production Focusing on Cellulosic Material Pre-Treatment and acid hydrolysis time, Artig. TÉCNICO / Tech. Artic 2019; 80: 59-66.

[95] Beck-Candanedo S, Roman M, Gray DG. Effect of reaction conditions on the properties and behavior of wood cellulose nanocrystal suspensions. Biomacromol 2005; 6: 1048-1054. https://doi.org/10.1021/bm049300p

[96] Urena-Benavides EE, Ao G, Davis VA, Kitchens CL. Rheology, and phase behavior of lyotropic cellulose nanocrystal suspensions. Macromol 2011; 44: 8990-8998. https://doi.org/10.1021/ma201649f

[97] Onasager L. The effect of shape on the interaction of colloidal paticles. Ann N Y Acad Sci 1949; 51 (4): 627-659. https://doi.org/10.1111/j.1749-6632.1949.tb27296.x

[98] Hamad WY, Hu TQ. Structure process yield interrelation in nanocrystalline cellulose extraction. Can J Chem Eng 2010; 88 (3): 392-402.

https://doi.org/10.1002/cjce.20298

[99] Kelly JA, Shopsowitz KE, Ahn JM, Hamad WY, MacLachlan MJ. Chiral nematic stained glass: Controlling the optical properties of nanocrystalline cellulose-templated materials. Langmuir 2012; 28 (50): 17256-17262. https://doi.org/10.1021/la3041902

[100] Schlesinger M, Giese M, Blusch LK, Hamad WY, Maclachlan MJ. Chiral nematic cellulose-gold nanoparticle composites from mesoporous photonic cellulose. Chem Commun 2015; 51(3): 530-533. https://doi.org/10.1039/C4CC07596J

[101] Lizundia E, Nguyen TD, Vilas JL, Hamad WY, Maclachlan MJ. Chiroptical luminescent nanostructured cellulose films. Mater Chem Front 2017; 1(5): 979-987. https://doi.org/10.1039/C6QM00225K

[102] Leung ACW, Hrapovic S, Lam E, Liu Y, Male HB, Mahmoud KA, Luong JHT. Characteristics and properties of carboxylated cellulose nanocrystals prepared form a novel one-step procedure. Nano Macro Small 2011; 7: 302-305. https://doi.org/10.1002/smll.201001715

[103] Waldemer RH, Tratnyek PG, Johnson RL, Nurmi AJ. Oxidation of Chlorinated Ethenes by Heat-Activated Persulfate: Kinetics and Products. Env Sci Technol 2007; 41: 1010-1015. https://doi.org/10.1021/es062237m

[104] Castro-Guerrero CF, Gray DG. Chiral nematic phase formation by aqueous suspensions of cellulose nanocrystals prepared by oxidation with ammonium persulfate. Cellulose 2014; 21: 2567-2577. https://doi.org/10.1007/s10570-014-0308-1

[105] Rampazzo R. Alkan D, Gazzotti S, Ortenzi MA, Piva G, Piergiovanni L. Cellulose Nanocrystals form lignocelllosics Raw materials, for oxygen barrier coatings on food packaging films. Packag Technol Sci 2017; 30: 645-661. https://doi.org/10.1002/pts.2308

[106] Turbak AF, Snyder FW, Sandberg KR. Micro fibrillared cellulose, a new cellulose product. Properties, uses and commercial potential. J Appl Polym Sci Symp 1983; 37: 797813.

[107] Pääkkö M, Ankerfors $M$, Kosonen H, Nykänen A, Ahola S Österberg M, Ruokolainen J, Laine J, Larsson PT, Ikkala O, Lindström T. Enzymatic hydrolysis combined with mechanical shearing and high-pressure homogenization for nanoscale cellulose fibrils and strong gels. Biomacromol 2007; 8: 19341941. https://doi.org/10.1021/bm061215p 
[108] Pawlowski WP, Gilbert RD, Formes RE, Purrington,ST. The thermotropic and lyotropic liquid-crystalline properties of acetoacetoxypropyl cellulose. J Polym Sci Pt B Polym Phys 1987; 25: 2293-2301.

https://doi.org/10.1002/polb.1987.090251107

[109] Hsiao BS, Stein RS, Deutscher K, Winter HH. Optical anisotropy of a thermotropic liquid-crystalline polymer in transient shear. J Polym Sci Pt B Polym Phys 1990; 28: 1571-1588. https://doi.org/10.1002/polb.1990.090280912

[110] Demus D, Richter L. Texture of liquid crystals, Verlag Chemie, Weinheim. New York, 1978.

[111] Dierking I. Textures of liquid crystals, Wiley-VCH, Weinheim, New York, 1990

[112] Piorkowska E, Rutledge GC. Handbook of Polymer Crystallization. Wiley-Vch Verlag GmbH \& Co., 2013; p. 489. ISBN: 978-0-470-38023-9 498 Pages.

[113] Ohlendorf P, Greine A. Synthesis of liquid crystalline thioether- functionalized hydroxypropyl cellulose esters. Polym Chem 2015; 6: 2734-2739. https://doi.org/10.1039/C4PY01709A

[114] Sackmann H, Demus D. The problems of polymorphism in liquid crystals. Mol Cryst Liq Cryst 1973; 21: 239-273. https://doi.org/10.1080/15421407308083321

[115] Demus D, Stegemeyer H (Eds). Topics in Physical Chemistry: Liquid Crystals. Steinkopff Verlag, Darmstadt, 1994.

[116] Dayan S, Gilli JM, Sixou P. Rheological studies of cellulose derivatives solutions 1983; 28: 1527-1534. https://doi.org/10.1002/app.1983.070280424

[117] Dai Q, Khan SA, Kadla JF. Transient rheological behavior of lyotropic (acetyl) (ethyl)cellulose/m-cresol solutions. Cellulose 2006; 13: 213-223 https://doi.org/10.1007/s10570-005-9027-y
[118] Papkov SP, Kulichikhin VG, Kalmykova VD, Malkin AY. Rheological properties of anisotropic poly (para-benzamide) solutions. J Polym Sci Polym Phys Ed 1974; 12 (9): 17531770.

https://doi.org/10.1002/pol.1974.180120903

[119] Grinshpan DD, Tret S M, Tsygankova NG, Makarevich SE. Savitskaya TA. Rheological studies of the highconcentration cellulose sulphate- acetate solutions. J Eng Phys Thermophys 2005; 78 (5): 41-47. https://doi.org/10.1007/s10891-006-0007-3

[120] Grinshpan DD, Savitskaya TA, Tsygankova NG, Makarevich SE, Tretsiakova S M, Nevar TN. Cellulose acetate sulfate as a lyotropic liquid crystalline polyelectrolyte: Synthesis, properties, and application. Int J Polym Sci 2010; 2010: Article ID 831658. https://doi.org/10.1155/2010/831658

[121] Basta AH, Lotfy VF, Micky JA, Salem AM. Liquid crystal behavior of cellulose nanoparticles-ethyl cellulose composites: Preparation, characterization, and rheology. J Appl Polym Sci 2021; 138(12): 50067. https://doi.org/10.1002/app.50067

[122] Basta AH, Lotfy VF, Micky JA. Salem AM. Hydroxypropylcellulose-Based Liquid Crystal Materials. Carbohydr Polym Technol Appl 2021; 2: 100103 https://doi.org/10.1016/j.carpta.2021.100103

[123] Dayan S, Gilli MJ, Sixou P. Rheological studies of cellulose derivatives solutions. J Appl Polym Sci 1983; 28 (4): 15271534.

https://doi.org/10.1002/app.1983.070280424

[124] Bheda J, Fellers JF, White J. Phase behavior and structure of liquid crystalline solutions of cellulose derivatives. Colloid Polym Sci 1980; 258: 1335-1342. https://doi.org/10.1007/BF01668781

https://doi.org/10.6000/1929-5995.2021.10.9

(C) 2021 Basta et al.; Licensee Lifescience Global.

This is an open access article licensed under the terms of the Creative Commons Attribution Non-Commercial License (http://creativecommons.org/licenses/by-nc/3.0/) which permits unrestricted, non-commercial use, distribution and reproduction in any medium, provided the work is properly cited. 